\author{
Oliver A. Shergold \\ Norman A. Fleck ${ }^{1}$ \\ Department of Engineering, \\ Cambridge University, Trumpington Street, \\ Cambridge, CB2 1PZ, UK
}

\section{Experimental Investigation Into the Deep Penetration of Soft Solids by Sharp and Blunt Punches, With Application to the Piercing of Skin}

An experimental study has been conducted on the penetration of silicone rubbers and human skin in vivo by sharp-tipped and flat-bottomed cylindrical punches. A penetrometer was developed to measure the penetration of human skin in vivo, while a conventional screw-driven testing machine was used to penetrate the silicone rubbers. The experiments reveal that the penetration mechanism of a soft solid depends upon the punch tip geometry: a sharp tipped punch penetrates by the formation and wedging open of a mode I planar crack, while a flat-bottomed punch penetrates by the growth of a mode II ring crack. The planar crack advances with the punch, and friction along the flanks of the punch leads to a rising load versus displacement response. In contrast, the flatbottomed punch penetrates by jerky crack advance and the load on the punch is unsteady. The average penetration pressure on the shank cross section of a flat-bottomed punch exceeds that for a sharp-tipped punch of the same diameter. In addition, the penetration pressure decreases as the diameter of the sharp-tipped punch increases. These findings are in broad agreement with the predictions of Shergold and Fleck [Proc. R. Soc. London, Ser. A (in press)] who proposed models for the penetration of a soft solid by a sharptipped and flat-bottomed punch. [DOI: 10.1115/1.1992528]

\section{Introduction}

The deep penetration of a soft solid by a punch is of widespread technological importance, with applications ranging from the piercing of mammalian skin by a hypodermic needle (or by a liquid jet) in administering an injection, to the failure of rubber seals or tires by the penetration of a foreign body, such as a nail. The dependence of skin perforation upon the mechanical properties of skin, and the shape of the penetrator, is also relevant to the function and evolution of mammalian dentition: the successful predator must have sufficiently strong jaws and sharp teeth to cause skin perforation. And in remote robotic surgery, as well as in training simulators for surgical techniques, it is important to quantify the resistance of tissue to penetration [1].

1.1 Deep Penetration Models. The penetration mechanism observed for soft solids is different from that for strong, ductile solids such as metals, soils, and polymers. Deep penetration of strong solids involves radial expansion of material at the penetrator tip [2,3]. Bishop et al. [2] modeled penetration by the expansion of a cavity in an elastic-ideally plastic solid, and argued that the penetration pressure is comparable to the cavitation pressure $p_{c}$, as defined by the pressure to expand the cavity from zero initial radius to a finite final radius. They showed that the cavitation pressure for an expanding spherical cavity is close to that for a cylindrical cavity and so the precise details of the cavity shape are relatively unimportant in the prediction of the penetration pressure. Typically, for metals $p_{c}$ is on the order of 4-5 times the uniaxial yield strength, depending upon the yield strain and the

\footnotetext{
${ }^{1}$ Corresponding author.

Contributed by the Bioengineering Division for publication in the JouRnal of Biomechanical Engineering. Manuscript received by the Bioengineering Division May 21, 2004; revision received February 18, 2005. Associate Editor: Andrew D. McCulloh.
}

strain hardening rate.

Despite the ubiquitous nature of soft solid penetration, the existing literature provides little insight into the underlying mechanisms of penetration. A limited number of experimental studies indicate that the deep penetration of skin and rubber involves cracking of the soft solid, followed by substantial reversible deformation [4-6]. These studies also suggest that the crack geometry is sensitive to the punch tip geometry and to the material properties of the penetrated solid.

Stevenson and Abmalek [6] showed that a cylindrical, flatbottomed punch of radius $R$ penetrates natural rubbers by the formation of a mode II ring crack that propagates ahead of the penetrator tip, as shown in Fig. 1(a). The propagating ring crack forms a column, with an undeformed diameter of $2 b$ and height $\ell$, as shown in Fig. 1(b). In this paper we shall demonstrate that a sharp-tipped punch penetrates silicone rubber and skin by the formation of a planar mode I crack ahead of the tip as shown in Fig. $2(a)$. The crack faces are wedged open by the advancing punch (Fig. 2(b)), but on punch removal the planar crack closes (Fig. $2(c)$ ). In this final, relaxed configuration the crack length is $2 a$.

In a companion paper Shergold and Fleck [7] have developed micromechanical models for the deep penetration of a soft solid by the two mechanisms shown in Figs. 1 and 2. They considered mammalian skin and silicone rubbers, and treated them as an incompressible, hyperelastic, isotropic solid described by a one term Ogden [8] strain energy function of the form

$$
\phi=\frac{2 \mu}{\alpha^{2}}\left(\lambda_{1}^{\alpha}+\lambda_{2}^{\alpha}+\lambda_{3}^{\alpha}-3\right)
$$

where $\phi$ is the strain energy density per undeformed unit volume, $\alpha$ is a strain hardening exponent, $\mu$ is the shear modulus under infinitesimal straining, and $\lambda_{1}, \lambda_{2}, \lambda_{3}$ are the three principal stretch ratios.

Shergold and Fleck [7] calculated the quasistatic steady-state 

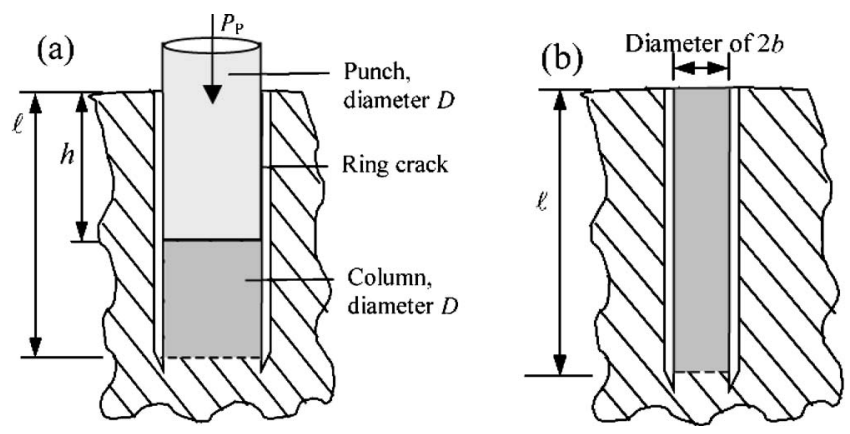

Fig. 1 (a) Steady-state penetration of a soft solid by a flat punch, $(b)$ stress-free configuration after punch removal

penetration load for both modes of punch advance (sharp-tipped or flat-bottomed) by equating the work done in advancing the punch to the sum of the fracture work and the strain energy stored in the solid: wave effects are ignored. Pertinent details of these penetration models are now given.

1.2 Penetration Model for a Flat-Bottomed Punch. Consider a frictionless, flat-bottomed, rigid cylindrical punch of radius $R$ penetrating a semi-infinite block, as sketched in Fig. 1(a). A ring crack propagates ahead of the penetrator tip forming a column, which in the undeformed configuration has a radius $b$ and a length $\ell$, see Fig. 1(b). The punch shortens the column from an undeformed length $\ell$ to a compressed length $(\ell-h)$. Simultaneously, the radius of the column increases from $b$ to $R$, due to incompressibility. The penetration load $P_{F}$ is estimated by equating the work done in advancing the punch to the sum of the crack work and the strain energy $S$ in the penetrated solid. There are two contributions to $S$, that due to compression of the column, $S_{C}$, and that due to expansion of the hole, $S_{H}$.

Consider steady state penetration of the punch at a fixed load $P_{F}$. In the current state the punch has descended by a depth $h$. The work done by the punch upon advancing by an increment $\delta h$ is given by

$$
P_{F} \delta h=2 \pi b J_{\mathrm{IIC}} \delta \ell+\frac{\partial S_{C}}{\partial \ell} \delta \ell+\frac{\partial S_{H}}{\partial \ell} \delta \ell
$$

where $J_{\text {IIC }}$ is the toughness of the material to mode II crack propagation. The quantity $\partial S_{C} / \partial \ell$ is the work done per unit depth (in the undeformed configuration) in order to compress the column beneath the punch by an axial stretch factor of $\lambda_{z}=b^{2} / R^{2}$, upon noting incompressibility. $\partial S_{H} / \partial \ell$ is the energy stored within unit thickness (undeformed) of the solid external to the hole. Explicit expressions for $\partial S_{C} / \partial \ell$ and $\partial S_{H} / \partial \ell$ are given by Shergold and Fleck [7]. Volume conservation of the column gives

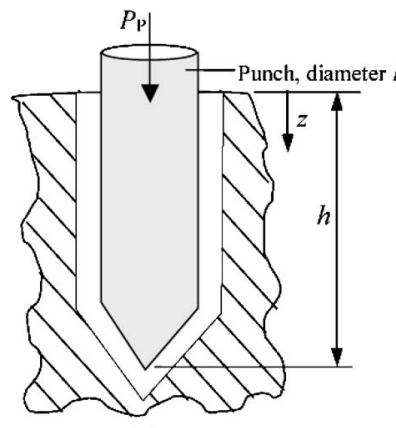

(a)

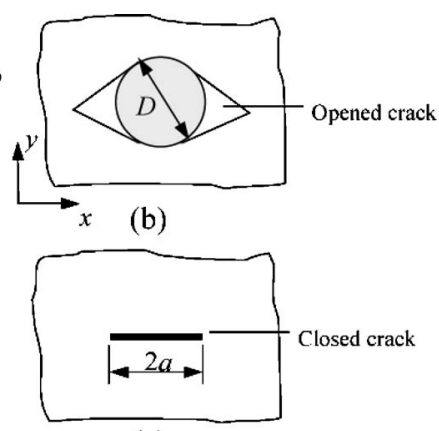

(c)
Fig. 2 (a) Penetration of a soft solid by a sharp-tipped punch, (b) crack opened to allow punch advance, (c) crack closed after punch removal

$$
\pi R^{2}(\ell-h)=\pi b^{2} \ell
$$

and, thereby the relation between $h$ and $\ell$. The crack dimensions are such that the load on the punch is minimized; see Shergold and Fleck [7] for additional details.

1.3 Penetration Model for a Sharp Punch. Consider a frictionless, rigid cylindrical punch of radius $R$ with a conical tip pushed into a semi-infinite block, as shown in Fig. 2. The solid tears and opens at the tip of the punch. The detailed solution for the punch tip requires a full 3D calculation; however, we can consider punch advance by $\delta \ell$ as equivalent to creating a plane strain crack of length $2 a$ in a slice of thickness $\delta \ell$, and then opening the crack to accommodate the punch. This energy balance approach is accurate when the strain energy density in each material element is independent of strain path.

Consider the steady state advance of the punch by an axial increment $\delta \ell$ due to a load $P_{S}$. The work done by the punch in effecting this advance is $P_{S} \delta \ell$. This work increment balances the energy $\delta W_{C}$ required to form a crack of length $2 a$ in a solid slice of thickness $\delta \ell$, see Fig. 2(b), and the strain energy stored in the solid $\delta S_{E}$ upon opening the crack to accommodate a circular cylindrical inclusion of radius $R$, see Fig. 2(c). Hence,

$$
P_{S} \delta \ell=\delta W_{C}+\delta S_{E}
$$

The work required to create the crack, $\delta W_{C}$, is determined by the mode I toughness of the material, $J_{\mathrm{IC}}$ and is given by

$$
\delta W_{C}=2 J_{\mathrm{IC}} a \delta \ell
$$

The work $\delta S_{E}$ required to wedge open the crack is calculated by finite element methods in Shergold and Fleck [7].

For both geometries of punch tip the models predict that the penetration pressure on the shank cross section of the punch increases with diminishing punch radius $R$, and with increasing values of toughness $J_{C}$ (mode I or mode II), shear modulus $\mu$ and strain hardening capacity of solid $\alpha$. A comparison of the flatbottomed and sharp-tipped penetration models suggests that the penetration pressure for a flat-bottomed punch is two to three times that for a sharp-tipped punch (assuming that the mode I and mode II toughnesses are equal). The experimental results of the current study are compared with the theoretical predictions in the companion paper of Shergold and Fleck [7].

1.4 The Measured Penetration Force for Soft Solids. A number of researchers $[1,9-18]$ have studied the force required to penetrate mammalian skin and rubber by needles, knives and punches. Unfortunately, none of these studies provide sufficient data to validate the penetration models of Shergold and Fleck [7], but a few broad conclusions can be drawn from them. The penetration force decreases with increasing sharpness of penetrator [9], and is sensitive to the type of tissue being penetrated: the penetration force for fat is significantly lower than that for skin and muscle [10], while the penetration force for human skin is lower than that for pig skin [1]. The penetration force also depends upon the degree of pre-stretch of the skin $[12,13]$ and the velocity of the penetrator $[1,12]$.

1.5 Outline of the Paper. The aim of this paper is to provide the physical justification and a quantitative comparison for the sharp-tipped punch and flat-bottomed punch penetration models of Shergold and Fleck [7]. Other head-shapes, such as hemispherical punches, are also of interest but are beyond the scope of the present study. Silicone rubber is selected as a model material for skin, and the relevant mechanical properties are reported for silicone rubbers and human skin. Penetration experiments into human skin in vivo and rubber blocks with sharp-tipped and flatbottomed punches are then described. The penetration mechanism is identified for each material class and punch tip geometry, and strategies are outlined for deducing the steady-state punch-tip pen- 


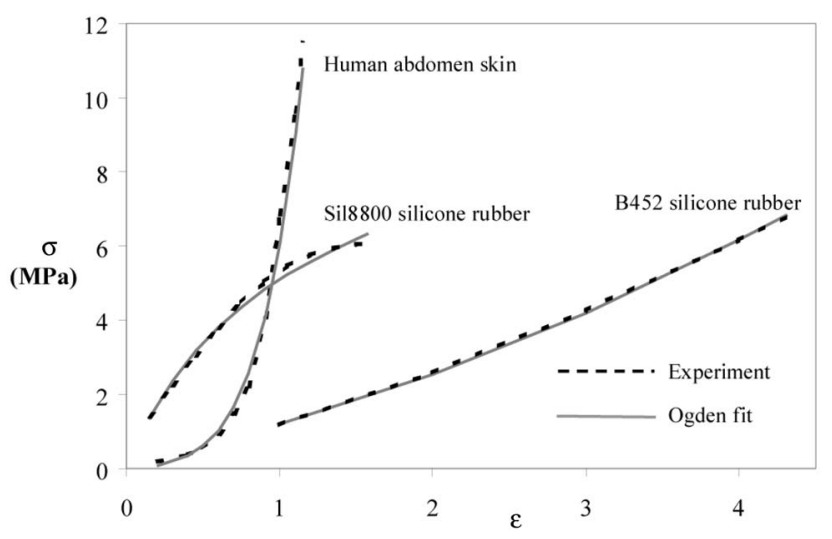

Fig. 3 Tensile uniaxial nominal stress versus nominal strain response for two silicone rubbers [44] and human skin [19]

etration load from the observed responses. The paper concludes with a comparison of the experimental results and with predictions by the penetration models.

\section{The Selection of Silicone Rubber as a Skin Substi- tute}

2.1 A Review of the Mechanical Properties of Skin. The mechanical properties (uniaxial stress versus strain and toughness) of skin are reviewed. These mechanical properties will be used to identify a suitable rubber as a skin substitute.

2.1.1 Constitutive Behavior. The tensile uniaxial engineering stress versus strain response of human skin as measured by Jansen and Rottier [19] is taken to represent the constitutive response of human skin. Figure 3 shows Jansen and Rottier's [19] results for skin samples taken $80 \mathrm{~mm}$ laterally from the median line between the umbilic and pubic area and tested at a strain rate of $0.01 \mathrm{~s}^{-1}$. The engineering stress versus strain response is concave (Jshaped) and the sample undergoes significant strain hardening at engineering strains in excess of 0.6. This J-shaped stress versus strain curve is typical for mammalian skin, although the rate of strain hardening varies from species to species [20].

A one-term Ogden function gives a reasonable representation of the stress versus strain response of human skin: the Ogden fit (shear modulus $\mu=0.11 \mathrm{MPa}$ and strain hardening exponent $\alpha$ $=9$ ) to Jansen and Rottier's data is included in Fig. 3. The Young's modulus $E$ of human skin associated with the curve-fitted value of shear modulus $\mu$ is $E=0.3 \mathrm{MPa}$; this is in reasonable agreement with tensile in vivo measurements of the Young's modulus reported by Clark et al. [21] (0.4 MPa to $0.8 \mathrm{MPa})$ and by Manschott and Brakee [22] (0.5 MPa).

Jansen and Rottier's [19] data are only an approximation to the constitutive behavior of skin, as there is large variability in skin responses depending upon the individual, the subject's age, the location on the body from where the sample was taken from, and to the method of storing the sample prior to testing [19,23]. In addition, Jansen and Rottier's [19] data does not capture the ortho-
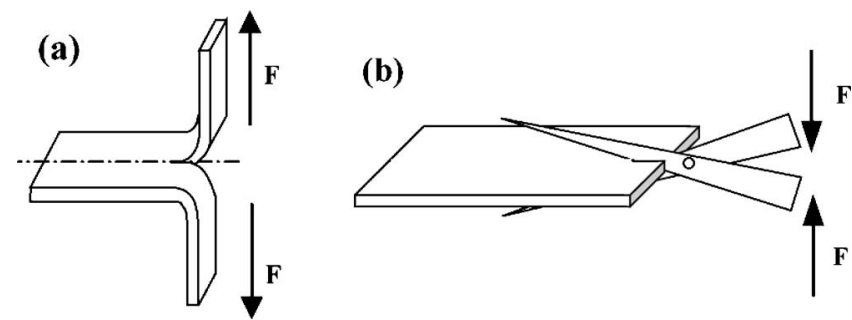

Fig. 4 Sketches of tests used to measure the toughness of a solid, (a) the trouser tear test and (b) the scissor tear test

tropic constitutive response of skin arising from the preferential alignment of the collagen fibers in the dermal layer [24-26]. These collagen fibers are aligned in the direction of maximum skin tension, thereby defining the Langer's lines. Consequently, the onset of strain hardening begins at lower strains when the skin is stretched in vivo parallel to the direction of maximum skin tension, compared with stretching perpendicular to the direction of maximum skin tension [22]. When a skin sample is excised from the body, the sample contracts, but the preferential alignment of the fibers is retained, and the skin's constitutive response remains orthotropic [26].

2.1.2 Skin Toughness. Mixed mode crack growth studies have been conducted on mammalian tissue using trouser tear and scissor cutting tests, as shown in Fig. 4. In the trouser tear test a rectangular sample is cut from a sheet of material and partially slit along its longitudinal length. Each leg is bent at 90 deg to the longitudinal plane of the specimen and clamped in a screw-driven testing machine, as shown in Fig. 4(a). The legs are pulled apart and the force versus displacement response recorded. If the strain in the legs is small, the work done in pulling the legs apart equals the fracture work in extending the slit [27]. However, for soft materials such as skin, the strain in the legs of the specimen is not small and must be accounted for when calculating the toughness [28]. Skin also exhibits hysterisis [25,29] and for high strains it is no longer valid to equate the external work performed during the test to the recoverable elastic strain energy in the material.

Following the work of Atkins and Mai [30], Pereira et al. [31] developed a scissor cutting test to overcome the problems associated with the trouser tear test. A schematic of the scissor cutting test is shown in Fig. 4(b). A specimen is mounted between the open blades of a pair of scissors. Upon applying a force to the scissors the specimen is cut. Material deformation is localized in the vicinity of the scissor blades. The work done in closing the scissor handles is equated to the fracture work in extending the cut.

Table 1 lists the toughness of various biological tissues as measured by the trouser tear test or scissor cutting test. These experiments highlight the importance of test geometry and orientation of the sample upon the measured toughness. The toughness of skin is dependent upon the structure of the collagen network: the toughness increases with increasing collagen density [33-35] and is

Table 1 Tear energy of mammalian skin

\begin{tabular}{llcc}
\hline \hline Reference & \multicolumn{1}{c}{ Tissue type } & Test method & $\begin{array}{c}\text { Average tear energy } \\
\pm 1 \text { s.d. }\left(\mathrm{kJ} \mathrm{m}^{-2}\right)\end{array}$ \\
\hline Pereira et al. [31] & Human skin (hand) & scissor & $2.5 \pm 0.3$ \\
Purslow [32] & Rat skin (random direction) & scissor & $0.6 \pm 0.2$ \\
Atkins and Mai [30] & Rat skin (perpendicular to spine) & trouser & $13.2 \pm 1.8$ \\
& Rat skin (parallel to spine) & trouser & $26.9 \pm 2.7$ \\
\hline \hline
\end{tabular}


Table 2 Mechanical properties of common rubber compounds (from Roff and Scott [43]) and mammalian skin

\begin{tabular}{|c|c|c|c|c|c|}
\hline & & Skin & $\begin{array}{l}\text { Silicone } \\
\text { rubber }\end{array}$ & $\begin{array}{l}\text { Natural } \\
\text { rubber }^{\mathrm{a}}\end{array}$ & $\begin{array}{l}\text { Natural butyl } \\
\text { rubber }^{\mathrm{a}}\end{array}$ \\
\hline Young's modulus & $\mathrm{MPa}$ & $0.3-1.0$ & $1-2.8$ & $3.5-6$ & $5.3-6.1$ \\
\hline Tensile strength & $\mathrm{MPa}$ & $10-20$ & $3.5-15$ & $22-28$ & $14-23$ \\
\hline Breaking elongation & $\%$ & 100 & $40-800$ & $450-600$ & $310-500$ \\
\hline Tear strength & $\mathrm{kN} \mathrm{m}^{-1}$ & $2-20$ & $5-40$ & $70-140$ & $38-55$ \\
\hline Strain crystallizes & & No & No & Yes & Yes \\
\hline $\begin{array}{l}\text { Crystallization temperature } \\
\qquad\left(T_{m}\right)\end{array}$ & ${ }^{\circ} \mathrm{C}$ & $\cdots$ & -53 & 30 & -6 to $-20^{b}$ \\
\hline $\begin{array}{l}\text { Glass transition temperature } \\
\qquad\left(T_{g}\right)\end{array}$ & ${ }^{\circ} \mathrm{C}$ & $\cdots$ & -125 & -72 & -105 \\
\hline Density & $\mathrm{kg} \mathrm{m}^{-3}$ & 1176 & $960-980$ & \multicolumn{2}{|c|}{ 920-100 (unfilled vulcanizates) } \\
\hline Molecular weight & Daltons & $1 \times 10^{4}-3 \times 10^{6 \mathrm{c}}$ & $4 \times 10^{5}-1.5 \times 10^{6}$ & $<10^{5}-4 \times 10^{6}$ & $5 \times 10^{4}$ to $6.5 \times 10^{5 \mathrm{~d}}$ \\
\hline
\end{tabular}

${ }^{\mathrm{a}}$ Vulcanisates with 50 parts HAF carbon black per 100 rubber.

${ }^{\mathrm{b}}$ Depends upon ratio of butyl rubber to natural rubber.

${ }^{c}$ Range given for different molecular structures such as collagen, elastin and ground substance.

${ }^{\mathrm{d}}$ Depends upon polymerization method.

lower when the crack propagates parallel to the aligned collagen fibers, compared to cracking perpendicular to the fibers [31-33,35,36].

\subsection{A Review of the Mechanical Properties of Rubber. In} this study silicone rubber is chosen as a skin substitute because the toughness and constitutive response of silicone rubber are close to those of skin. The mechanical properties of three commonly used polymers (silicone rubber, natural rubber, and natural butyl rubber) are compared with those of human skin in Table 2. The table shows that the tear strength and tensile strength of silicone rubber are comparable to those for human skin, although silicone rubbers have greater failure strains. In contrast, natural rubbers and natural butyl rubbers typically have tensile strengths and tear strengths that are two to three times those of skin.

Silicone rubber is more representative of human skin than natural rubber and natural butyl rubber because silicone rubber does not strain crystallize, and its crystallization temperature is well below room temperature. The crystallization of a rubber leads to a rapid increase in the shear modulus [37]. In addition, crystalline rubbers exhibit crack-tip branching during tearing with a consequent increase in the measured toughness [38-42].

Two formulations of peroxide-cured silicone rubber are used as a skin substitute: B452 (off-white) supplied by Dunlop Precision Rubber (Shepshed, Loughborough) and Sil8800 (Red, 80 IRHD) supplied by Superior Seals (Wimborne, Dorset). Sil8800 is Superior Seals's trade name for an uncured formulation supplied by Dow Corning, with the product code S22062-85-02. Sil8800 contains a high proportion (10\%-30\% by weight) of ground quartz as a filler, and a small proportion of red iron oxide ( $<1 \%$ by weight) as a pigment. The formulation of the B452 rubber was not available as the supplier considered this information to be proprietary. However, SEM micrographs reveal that the Sil8800 rubber has a greater proportion of quartz filler than B452 rubber, with a corresponding increase in shear modulus, hardness and density, see Table 3.

Shergold and Fleck [44] performed uniaxial tension and compression tests on the two grades of silicone rubber at a strain rate of $0.3 \mathrm{~s}^{-1}$, see Fig. 3. The one-term Ogden fit for each rubber is included in Fig. 3 and the Ogden constants are given in Table 3. It can be seen that the one-term Ogden model gives a reasonable approximation to the stress versus strain curve observed for silicone rubber. Values for the mixed mode toughness $J_{C}$ of the silicone rubbers measured using a trouser tear test at a crack growth rate of $2 \times 10^{-4} \mathrm{~m} \mathrm{~s}^{-1}$ are included in Table 3 [20]. It is concluded from Table 3 that silicone rubbers are an approximate substitute for human skin: they have a somewhat higher modulus, a lower rate of strain hardening and a comparable toughness.

\section{Solid Punch Experiments}

An investigation has been conducted into the penetration of silicone rubber blocks (Sil8800 and B452) and human skin in vivo by sharp-tipped and flat-bottomed punches. The objective of these investigations was to determine the sensitivity of the penetration mechanism, and load on the punch, to the punch tip geometry. Details of the experiments are as follows, for a flat-bottomed punch, a hypodermic needle and a conically-tipped punch.

3.1 Puncture of Human Skin With a Hypodermic Needle and a Flat-Bottomed Punch. The test instrument sketched in Fig. 5 was developed in-house and manufactured to measure the load and displacement of a punch as it pierces the skin in vivo. The punch connects to a load cell, which in turn is attached to a connecting rod. The connecting rod slides inside of a bearing mounted at one end of an acrylic tube. A linear variable differential transformer (LVDT) measures the position of the punch as the connecting rod is moved. A spring within the LVDT keeps the punch retracted from the open end of the tube. Data acquisition from the load cell and the LVDT is by a National Instruments PCMCIA DAQ card installed in a laptop computer. A Matlab programme controls the data acquisition.

To operate the instrument, the open end of the tube is placed on the surface of the skin with the punch retracted. The human subject depresses the connecting rod at about $1 \mathrm{~mm} \mathrm{~s}^{-1}$ in order to cause the punch to pierce the skin. The advantage of manually driving the punch is that the human subject can immediately stop

Table 3 Mechanical properties of the solids used in the penetration experiments

\begin{tabular}{ccccccc}
\hline \hline Solid & Grade & $\mu(\mathrm{MPa})$ & $\alpha$ & $J_{C}\left(\mathrm{~kJ} \mathrm{~m}^{-2}\right)$ & $\begin{array}{c}\text { Density } \\
\left(\mathrm{kg} \mathrm{m}^{-3}\right)\end{array}$ & $\begin{array}{c}\text { Shore } \\
\text { hardness }\end{array}$ \\
\hline Silicone rubber & Sil8800 & 2.7 & 2.5 & 3.1 & 1550 & 80 \\
Silicone rubber & B452 & 0.40 & 3.0 & 3.8 & 1180 & 52 \\
Human skin & $\cdots$ & 0.11 & 9.0 & 2.5 & 1176 & $\cdots$ \\
\hline \hline
\end{tabular}




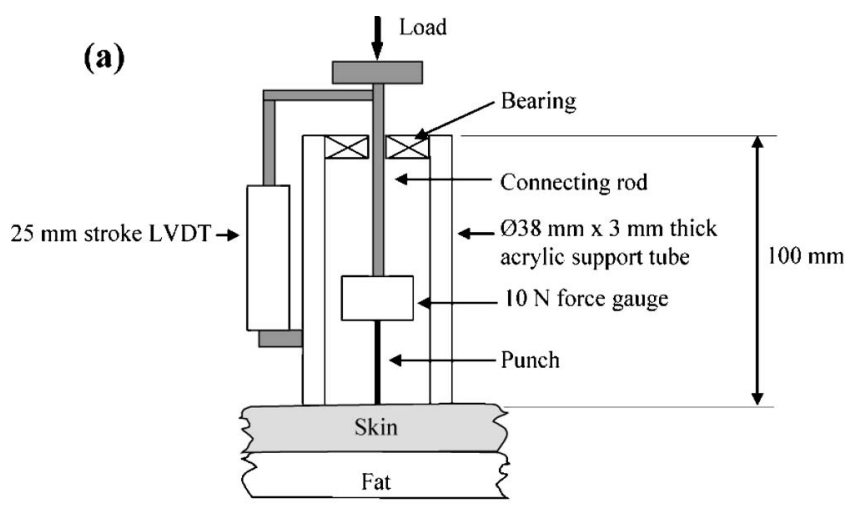

(b)

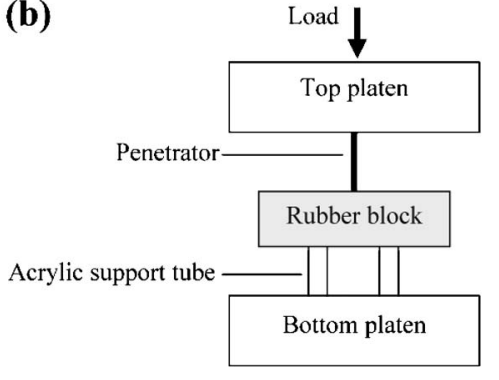

Fig. 5 (a) Hand-operated instrument for measuring the force required to penetrate the skin in vivo and $(b)$ rubber block penetration test configuration

the experiment when the penetration depth, or load on the punch, is considered excessive. However, the disadvantage of this test method is that the velocity of the punch cannot be accurately controlled.

Sterile hypodermic needles of diameter $0.3 \mathrm{~mm}$ and $0.6 \mathrm{~mm}$ were used as sharp tipped punches. A hypodermic needle has a chamfered tip, as shown in Fig. 6(a). The $0.3 \mathrm{~mm}$ diameter needle had a chamfer length of $1.4 \mathrm{~mm}$ and a chamfer angle of $12 \mathrm{deg}$, while the $0.6 \mathrm{~mm}$ diameter needle had a chamfer length of $2.5 \mathrm{~mm}$ and a chamfer angle of $14 \mathrm{deg}$. Flat-bottomed punches of diameter $0.3 \mathrm{~mm}$ and $0.5 \mathrm{~mm}$ were made from stainless steel wire mounted in a stainless steel Luer fitting, as shown in Fig. 6(b). These punches were autoclaved prior to use.

The abdomen was the first site chosen for the penetration tests, as this offered thicker skin and fat layers compared to most other regions of the body and is the preferred site for liquid jet injections. Digital pictures of the penetration sites were taken using a CCD camera attached to an Olympus stereoscopic microscope. However, it proved difficult for the subject to hold the abdomen still while a picture was taken. Better quality images were
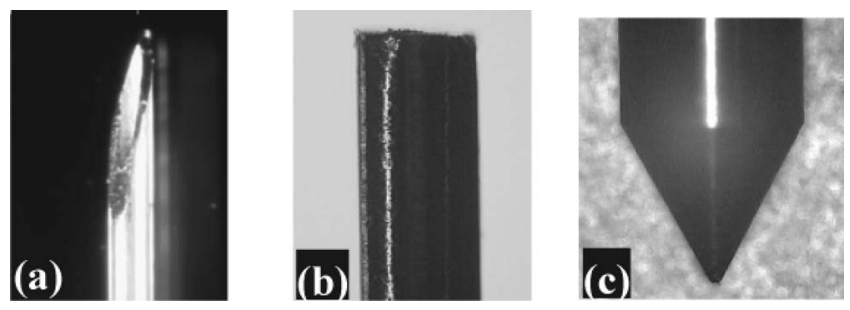

Fig. 6 Stainless steel punch tips used in the penetration experiments (not to scale) (a) $\varnothing 0.3 \mathrm{~mm}$ hypodermic needle, (b) $\varnothing 0.3 \mathrm{~mm}$ flat-bottomed punch, and (c) $\varnothing 2 \mathrm{~mm}$ sharp tipped needle

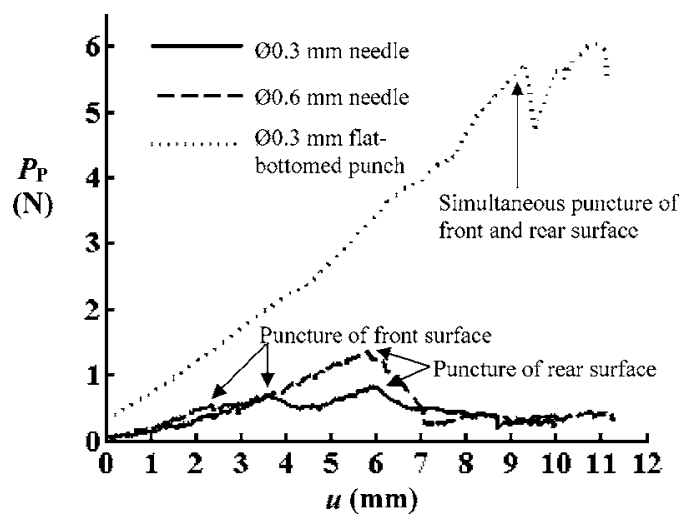

Fig. 7 Punch load versus displacement response for the penetration of lower arm skin by a hypodermic needle and penetration of abdomen skin by a flat-bottomed punch

achieved of penetration into the lower arm. The penetration site could be identified quickly before any blood seeped from the wound and obscured the surface of the skin.

3.2 Penetration of a Rubber Block by a Sharp-Tipped or Flat-Bottomed Punch. Punch penetration experiments were performed on B452 and Sil8800 silicone rubber samples. The B452 rubber samples comprised $50 \mathrm{~mm} \times 50 \mathrm{~mm}$ square blocks of thickness $10.6 \mathrm{~mm}$, cut from a $300 \mathrm{~mm} \times 300 \mathrm{~mm}$ sheet. The Sil8800 silicone rubber samples were supplied as $\varnothing 30 \mathrm{~mm}$ cylinders of thickness $12.0 \mathrm{~mm}$.

Sharp-tipped punches were manufactured by grinding a conically shaped tip with a $60 \mathrm{deg}$ inclusive angle onto the end of $\varnothing 0.5 \mathrm{~mm}, \varnothing 1.0 \mathrm{~mm}$, and $\varnothing 2.0 \mathrm{~mm}$ steel drill blanks, for example see Fig. 6(c). A $\varnothing 1.0 \mathrm{~mm}$ steel drill blank was used as a flat-bottomed punch. It proved difficult to investigate a wide range of flat-bottomed punch diameters: smaller punch diameters resulted in very small cracks that were difficult to observe and measure, while larger punch diameters resulted in substantial deformation of the rubber block prior to penetration.

In each test, the sample sat on an open-ended acrylic tube resting on the bottom platen of an Instron 5500R screw driven test machine, while the punch was mounted onto the top platen, see Fig. 5. The punch was driven into the sample at a speed of $0.8 \mathrm{~mm} \mathrm{~s}^{-1}$ until the punch tip emerged from the rear surface of the sample. The punch was removed, and the sample cut was sectioned on various planes using a scalpel blade to reveal the penetration site at different depths through the sample. Pictures were taken of the penetration site at these different depths using a CCD camera mounted onto a Leica compound microscope.

\section{Results}

4.1 Load Versus Displacement Response. A comparison is made of the load versus displacement response of a sharp-tipped and flat-bottomed punch as the punch penetrates each type of silicone rubber and skin. The load versus displacement responses for skin are shown in Fig. 7, for the $10.6 \mathrm{~mm}$ thick B452 rubber block in Fig. 8, and for the $12.0 \mathrm{~mm}$ thick Sil8800 rubber cylinders in Fig. 9. It was not possible to achieve penetration of skin in vivo with the $\varnothing 0.5 \mathrm{~mm}$ flat-bottomed punch and no force versus displacement data are presented for these tests. As expected, the load on a flat-bottomed punch is greater than the load on a sharptipped punch of equal diameter.

4.2 Observed Penetration Mechanisms. A crack was observed on the surface of the solid upon removal of the punch (flat-bottomed or sharp-tipped). The geometry of the crack depended upon the geometry of the punch: a ring crack was ob- 


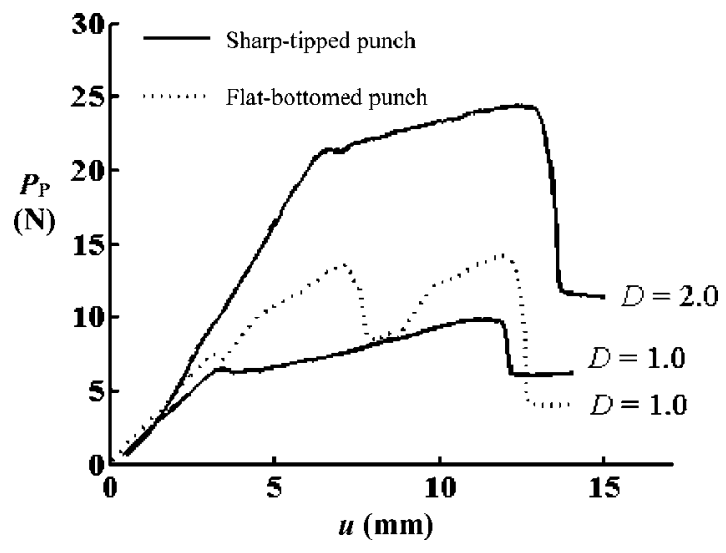

Fig. 8 Typical punch load versus displacement response for the penetration of $10.6 \mathrm{~mm}$ thick B452 rubber blocks by a sharp-tipped and a flat-bottomed punch. Punch diameter $D$ $(\mathrm{mm})$ indicated.

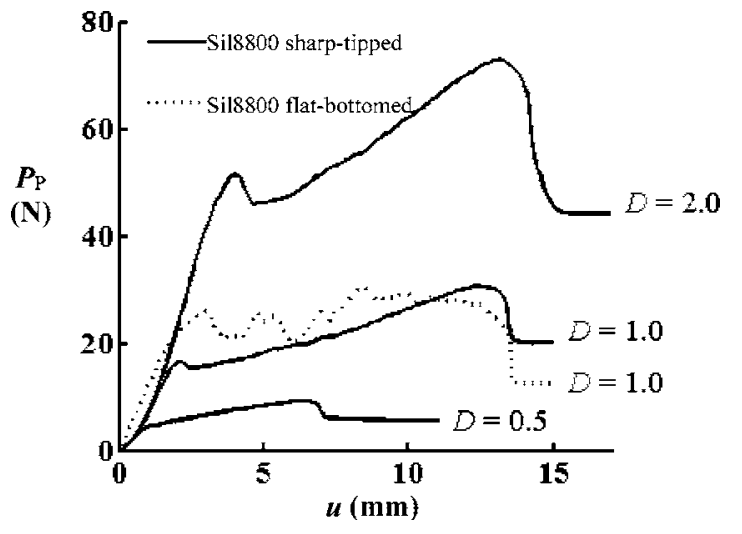

Fig. 9 Punch load versus displacement response for the penetration of $12.0 \mathrm{~mm}$ thick Sil8800 rubber blocks by a sharptipped and a flat-bottomed punch. Punch diameter $D(\mathrm{~mm})$ indicated.
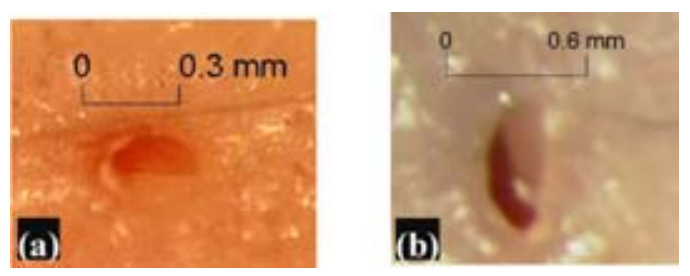

Fig. 12 (a) Penetration of the abdomen in vivo by a $\varnothing 0.3 \mathrm{~mm}$ flat-bottomed punch and $(b)$ penetration of the lower arm in vivo by a $\varnothing 0.3 \mathrm{~mm}$ hypodermic needle

served following penetration by a flat-bottomed punch, while a planar crack was observed following penetration by a sharp-tipped punch. These cracking mechanisms are sketched in Figs. 1 and 2.

Sections taken a posteriori reveal the ring crack or planar crack at varying depths through the rubber block. For example, Figs. 10 and 11 show the ring crack at different depths into Sil8800 and B452 silicone rubber blocks following penetration by a flatbottomed punch. The ring crack encompasses a column, which is shown emerging from the rear surface of the B452 block in Fig. $11(d)$. Figures 13 and 14 show the planar crack at different depths through a Sil8800 and B452 silicone rubber block following penetration by a sharp-tipped punch. Figure 14 also shows that the planar crack occasionally branched. We noted fewer incidences of crack branching as the punch diameter and as the shear modulus of the rubber increased.

Although it was not possible to section human skin following penetration by a hypodermic needle or flat-bottomed punch, a planar crack or hole was observed on the surface of the skin (see Fig. 12) and we conclude that the penetration mechanism is also by the growth of a planar crack or ring crack. This was confirmed by performing additional tests on pig tissue in vitro. Fresh samples of pig skin $(\approx 3.0 \mathrm{~mm}$ thick) and fat were obtained from a butcher and subjected to penetration by a flat-bottomed punch, sharp-tipped punch and hypodermic needle (all $0.5 \mathrm{~mm}$ in diameter) at a similar speed to the human skin penetration tests. Cross sections taken parallel to the skin surface at middepth revealed the cracking morphology, see Fig. 15. This figure shows that deep penetration involved formation of a mode II ring crack ahead of the flat punch and the formation of a mode I opening crack along the flanks of the sharp-tipped punch and hypodermic needle.
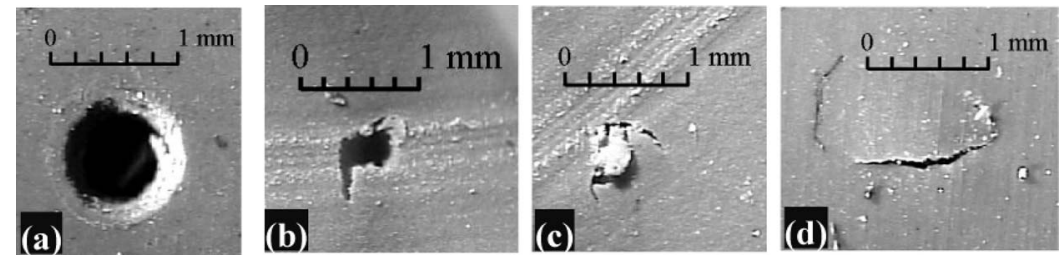

Fig. 10 Penetration of a Sil8800 rubber block by a $\varnothing 1 \mathrm{~mm}$ flat-bottomed punch. Sections are taken at a depth of (a) $0 \mathrm{~mm}$, (b) $1.8 \mathrm{~mm}$, (c) $9.5 \mathrm{~mm}$, and (d) $12.0 \mathrm{~mm}$ from the front surface of the block.
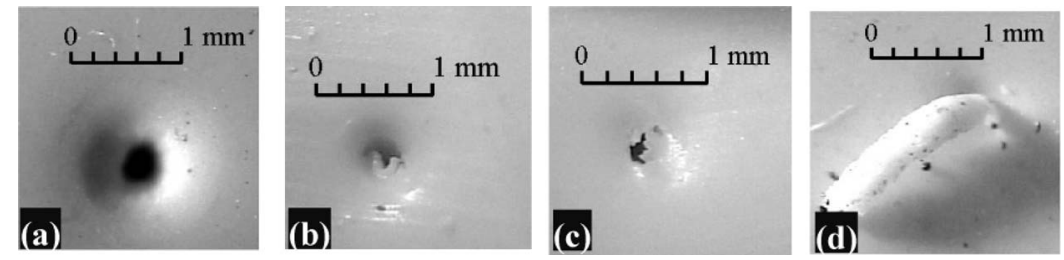

Fig. 11 Penetration of a B452 rubber block by a $\varnothing 1 \mathrm{~mm}$ flat-bottomed punch. Sections are taken at a depth of (a) $0 \mathrm{~mm},(b) 4.1 \mathrm{~mm},(c) 7.1 \mathrm{~mm}$, and (d) $10.6 \mathrm{~mm}$ from the front surface of the block. The column can be seen emerging from the rear surface of the block in picture $(d)$. 

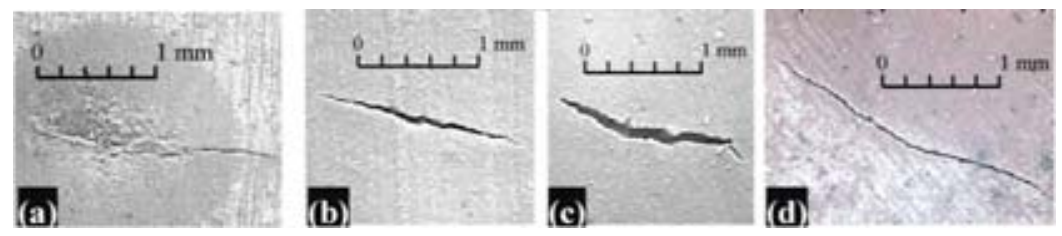

Fig. 13 Penetration of a Sil8800 rubber block by a $\varnothing 2 \mathrm{~mm}$ sharp-tipped punch. Sections are taken at a depth of (a) $0 \mathrm{~mm}$, (b) $4.5 \mathrm{~mm}$, (c) $8.5 \mathrm{~mm}$ and (d) $12.0 \mathrm{~mm}$ from the front surface of the block.

4.3 Longitudinal Sections of Cracked Silicone Rubber Blocks. SEM micrographs taken of B452 and Sil8800 rubber blocks highlight differences in how a ring crack or planar crack propagates through each type of rubber. In the case of Sil8800 rubber, the ring crack or planar crack branched away from the direction of punch advance, see Figs. $16(a)$ and $16(b)$. However, no crack branching was observed in the B452 rubber for either punch-tip geometry, see Figs. 16(c) and 16(d).

4.4 Measurement of Crack Geometry. The dependence of the diameter $2 b$ of the ring crack, and the length $2 a$ of the planar crack, was measured in the unloaded state. In the case of the planar crack the crack length was determined by measuring the distance between crack tips; for branched cracks the greatest distance between two crack tips was taken.

The dimensions of the ring crack are shown in Fig. 17 and the length of the planar crack are given in Fig. 18, following penetration of B452 and Sil8800 rubber blocks. Figure 17 demonstrates that the diameter of the ring crack is considerably smaller than the diameter of the flat-bottomed punch. We observe from Fig. 18 that the planar crack length increases as the diameter of the conicallytipped punch increases. We also note that the ratio of the crack length to punch diameter $(2 a / D)$ increases as the punch diameter increases.

The dimensions of the ring crack or planar crack attain steady state values with increasing depth. However, at the front and rear surface of the block the ring crack was approximately twice the diameter it displays at middepth. This tapering of the ring crack from the front surface of the block is evident in Fig. 16(c). For the case of the planar crack, the crack length was shorter on the front surface and longer on the rear surface of the block compared with the crack length at middepth. In the tests where the planar crack was longer on the front surface than at middepth, the crack had lengthened during punch removal (for example, see the results for penetration of Sil8800 rubber by a $\varnothing 2 \mathrm{~mm}$ conically-tipped punch). These observed changes in crack dimensions with depth are due to the change in constraint on the solid as the punch-tip advances. When the punch tip is at middepth the solid is taken to be in a state of plane-strain. In contrast, the front and rear surfaces of the block are unconstrained and substantial deformations occur in the direction of punch tip advance.

\section{Discussion}

5.1 Interpretation of the Load Versus Displacement Response. The initiation and propagation of the planar crack can be identified on the load versus displacement curve for each sharp-tipped punch penetration test, see Fig. 19(a). At the start of the penetration test the solid deforms under the advancing punch tip until a critical load reached. At this critical load a planar crack initiates beneath the punch tip and rapidly lengthens and opens, allowing the punch to penetrate the solid. Initiation of the crack involves a drop in the punch load. As the punch continues to penetrate the solid, the crack tunnels in a steady manner into the block at the speed of the advancing punch. Just prior to the punch tip breaking through the rear surface of the silicone rubber block, the load achieves a maximum value of $P_{\max }$ at a displacement of $h_{\max }$. Once the punch tip has broken through the rear surface of the block, the only contribution to the load on the punch is from friction, which attains a maximum value $F_{\max }$.

In the case of the flat-bottomed punch, the deformation of the solid and initiation of the ring crack can also be identified on the load versus displacement response, see Fig. 19(b).

However, in contrast to the sharp-tipped punch, the load on the flat-bottomed punch does not increase steadily as the punch penetrates the block. Instead, the load oscillates and the load drops are associated with the rapid propagation of the ring crack ahead of the advancing punch tip.

When a sharp-tipped or flat-bottomed punch has penetrated a distance $h$ into the block, the load on the punch $P_{P}(h)$ is the sum of the penetration load and the load $F_{P}(h)$ due to friction between the shaft of the punch and the surrounding solid. The penetration load is associated with the processes of crack formation and subsequent deformation of the solid. We now propose schemes for accounting for the friction load in order to determine the penetration load.

5.2 Strategy for Determining the Penetration Load for a Sharp-Tipped Punch. Consider a sharp-tipped punch that is penetrating a silicone rubber block. At low punch velocities, the growth and opening of the crack is quasistatic and wave effects are ignored. Figure 19(a) shows that the punch load achieves a maximum value $P_{\max }$ at a displacement of $h_{\max }$ just prior to the
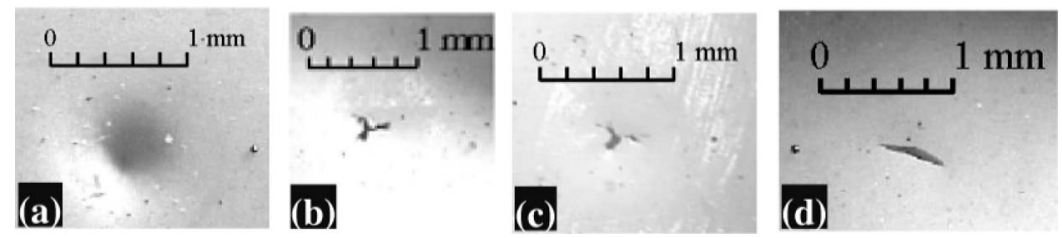

Fig. 14 Penetration of a B452 rubber block by a $\varnothing 1.0 \mathrm{~mm}$ sharp-tipped punch. Sections are taken at a depth of (a) $0 \mathrm{~mm}$, (b) $3.3 \mathrm{~mm}$, (c) $6.5 \mathrm{~mm}$ and (d) $10.6 \mathrm{~mm}$ from the front surface of the block. 

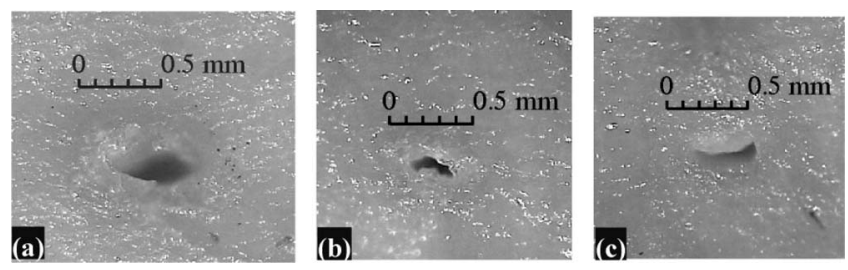

Fig. 15 Penetration of pig skin in vitro using (a) flat-ended punch, (b) sharp-tipped punch, and (c) hypodermic needle, each of diameter $0.5 \mathrm{~mm}$

punch tip breaking through the rear surface of the silicone rubber block. Once the punch tip has broken through the rear surface of the block, the only contribution to the load on the punch is from a friction load $F_{\max }$. We define the frictionless penetration load $P_{S}$ associated with the work done in advancing the punch through the process of crack formation and subsequent opening of the crack as

$$
P_{S}=P_{\max }-F_{\max }
$$

Relation (6) is also used to determine the penetration load $P_{S}$ associated with the penetration of skin by a hypodermic needle. The puncture of the front and rear surfaces of the skin layer can be identified on the sharp-tipped punch load versus displacement responses shown in Fig. 7. There is a significant drop in the punch load as the sharp-tipped punch punctures the rear surface of the skin layer and starts to penetrate the underlying fat layer. The investigations of O'Callaghan et al. [10] and Brett et al. [1] indicate that the force required to penetrate the fat layer is negligible. Consequently, we assume that the load on the punch following penetration of the skin layer is due to friction between the skin and punch.
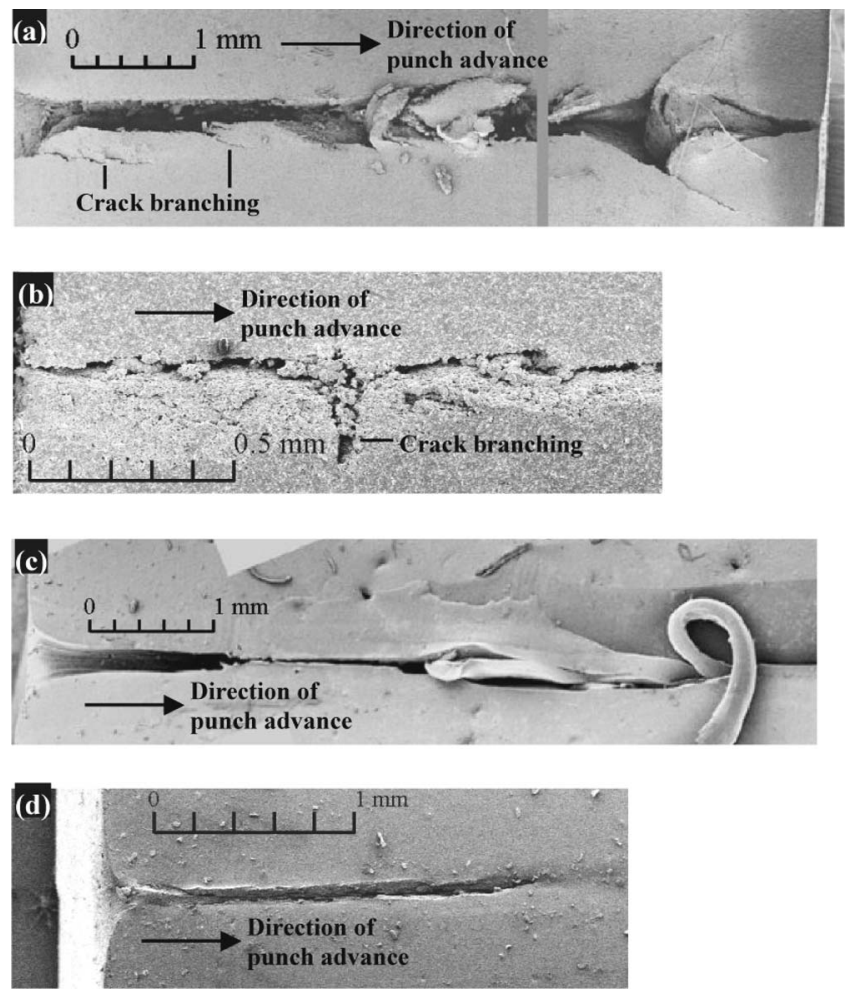

Fig. 16 Section through a Sil8800 silicone rubber block following penetration by (a) a $\varnothing 1.0 \mathrm{~mm}$ flat-bottomed punch and (b) a $\varnothing 1.0 \mathrm{~mm}$ sharp-tipped punch, and section through a B452 silicone rubber block following penetration by (c) a $\varnothing 1.0 \mathrm{~mm}$ flatbottomed punch and (d) a $\varnothing 1.0 \mathrm{~mm}$ sharp-tipped punch

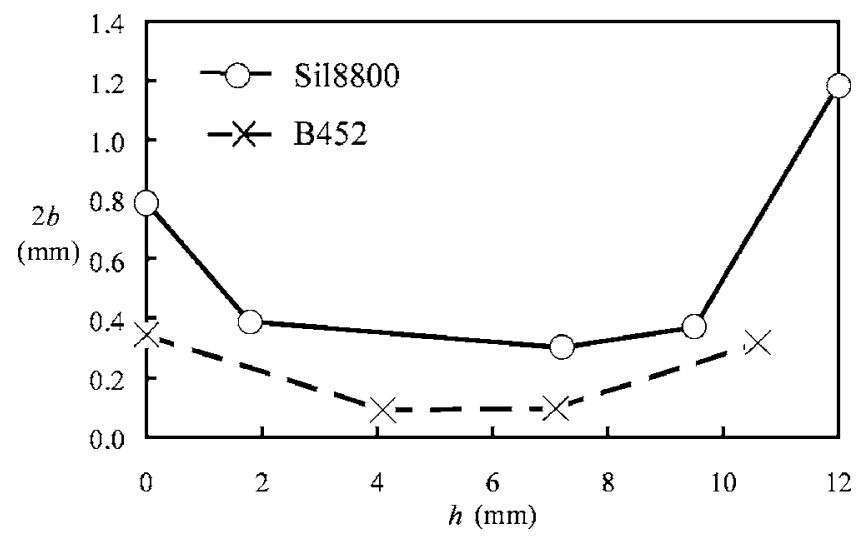

Fig. 17 Ring crack diameter $2 b$ versus depth $h$ into silicone rubber block following penetration by a $\varnothing 1.0 \mathrm{~mm}$ flat-bottomed punch

5.3 Strategy for Determining the Penetration Load for a Flat-Bottomed Punch. For the flat-bottomed punch the load on the punch oscillates and we must determine the average penetration load $P_{F a v e}$. The following scheme neglects any wave effects arising from the rapid propagation of the mode II crack into the block. When the punch is penetrating through the block, the load on the punch $P_{P}(h)$ at a depth $h$ into the block comprises a penetration load $P_{F}(h)$ and a friction load $F_{P}(h)$

$$
P_{P}(h)=P_{F}(h)+F_{P}(h)
$$

When the punch breaks through the rear surface of the block at a displacement $h_{\max }$, the only contribution to the load on the punch is from friction and this attains a maximum value $F_{\max }$, as shown in Fig. 19(b). We assume a linear increase in friction with punch depth $h$, giving

$$
F(h)=\frac{h}{h_{\max }} F_{\max } \quad 0 \leqslant h \leqslant h_{\max }
$$

Substitution of (8) into (7) allows the effects of the friction load to be compensated for, and the average penetration load $P_{F \text { ave }}$ can be determined by

$$
P_{\text {Fave }}=\frac{1}{N} \sum_{n=1}^{N} P_{n}-\frac{h_{n}}{h_{\text {max }}} F_{\text {max }}
$$

where $N$ is the number of data pairs $\left(h_{n}, P_{n}\right)$ recorded during the

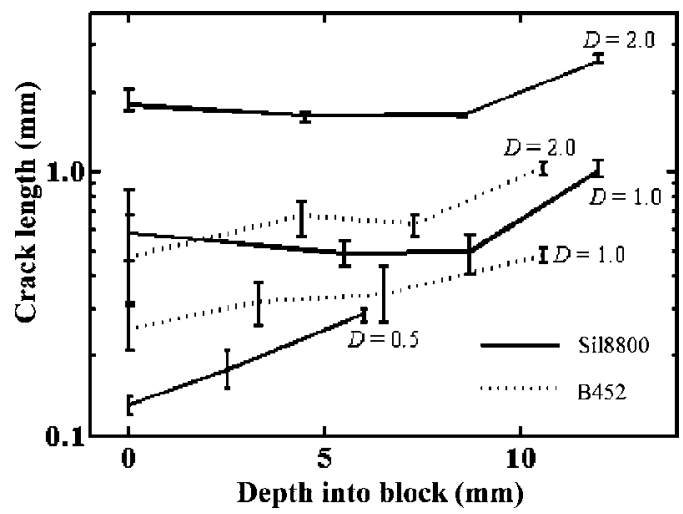

Fig. 18 Crack length $2 a$ versus depth into block following penetration by a sharp-tipped punch, punch diameter $D(\mathrm{~mm})$ indicated. Error bars represent maximum and minimum crack lengths from five tests. 

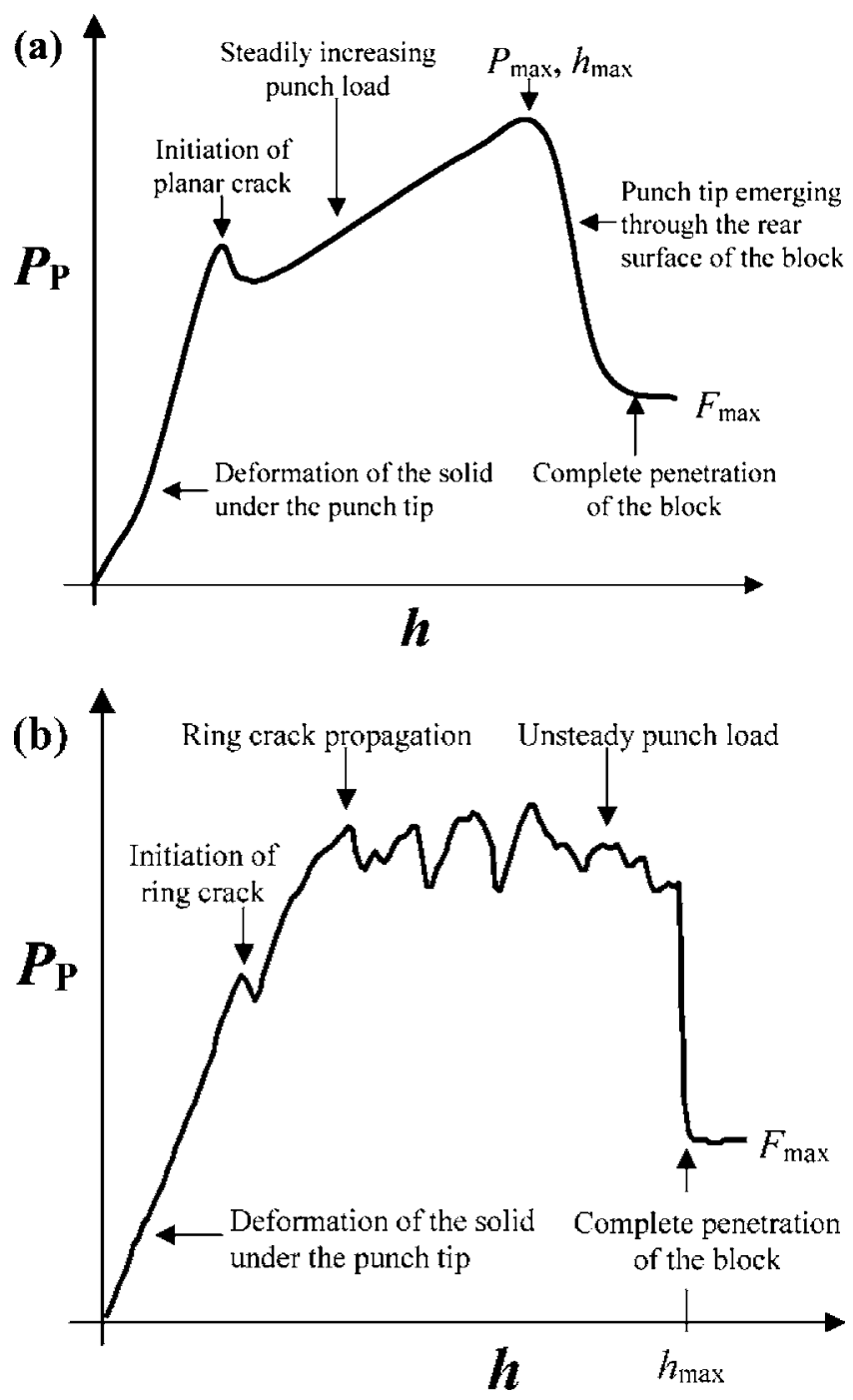

Fig. 19 Characteristics of the punch load versus displacement response for the penetration of a soft solid by (a) a sharptipped punch and $(b)$ a flat-bottomed punch

test after initial penetration of the front surface.

The above strategy could not be used for the penetration of skin by a flat-bottomed punch. Figure 7 shows the punch load versus displacement response of a flat-bottomed punch as it penetrates human skin in vivo. The penetration of the front and rear surfaces of the skin layer are not distinct, as only one significant drop in punch load is observed. The absence of two drops in punch load is because only the front surface of the skin layer has been penetrated. Assume that the friction load is small in comparison to the penetration load (reasonable if one considers the friction load associated with the penetration of skin by a sharp-tipped punch). Then we can define the average penetration load as

$$
P_{\text {Fave }}=\frac{1}{2}\left(P_{\text {max }}+P_{\text {min }}\right)
$$

where $P_{\max }$ is the peak load prior to the observed drop in punch load and $P_{\text {min }}$ is the subsequent local load minimum.

5.4 Comparison of the Penetration Pressures for Sharp and Blunt Punches. The average penetration pressure on the shank cross-section of a sharp-tipped punch $p_{S}$, and of a flatbottomed punch $p_{F}$, is calculated from the inferred frictionless penetration load. In the case of the sharp-tipped punch experiments the penetration load $P_{S}$ for human skin and silicone rubber is evaluated using (6). Additionally, the measurements of Frick
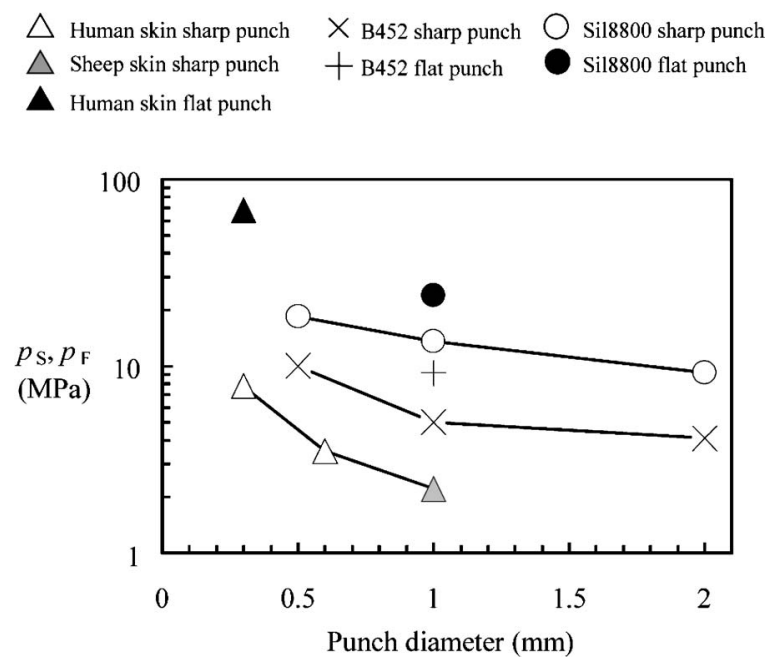

Fig. 20 Penetration pressure versus punch diameter for a flatbottomed and sharp-tipped punch

et al. [12] have been used to determine the value of $P_{S}$ associated with the penetration of sheep skin in vitro by a $\varnothing 1.0 \mathrm{~mm}$ suture needle. (Frick and co-workers removed strips of skin from a carcase and measured the injection force versus displacement relation using an instrumented needle. The skin was clamped at each end, with no additional support beneath it.) For the flat-bottomed punch experiments, the penetration load $P_{F \text { ave }}$ is calculated for the silicone rubbers using relation (9), and for human skin using relation (6).

Figure 20 shows a comparison of $p_{F}$ and $p_{S}$ versus punch diameter for the penetration of the silicone rubbers and human skin and sheep skin. This graph reveals that for silicone rubber the penetration pressure of a flat-bottomed punch is approximately twice that of a sharp-tipped punch of equivalent diameter, while for skin it is approximately eight times as large. As discussed by Shergold and Fleck [7], the high ratio of penetration pressure in skin for a flat punch versus a sharp punch may be associated with a high ratio of mode II toughness to mode I toughness. We also observe that in the case of the sharp-tipped punch, the penetration pressure decreases as the diameter of the punch increases. These experimental results are in agreement with the predictions of Shergold and Fleck [7].

The penetration models of Shergold and Fleck [7] reveal that the dimensionless penetration pressure $p_{S} / \mu$ or $p_{F} / \mu$ increases with the dimensionless group $J_{C} / \mu R$ and with the strain hardening exponent $\alpha$. Figure 21 shows the relationship between $p_{S} / \mu$ and $J_{\mathrm{IC}} / \mu R$ and $\alpha$ for the sharp-tipped punch penetration experiments on skin (human and sheep) and silicone rubber (B452 and Sil8800). The mechanical properties (toughness and shear modulus) given in Table 3 are used to calculate the values of $p_{S} / \mu$ and $J_{\mathrm{IC}} / \mu R$. The relevant properties of sheep skin are not available from the literature and so they are assumed to be the same as those for human skin.

The literature suggests that the measured toughness $J_{\text {IC }}$ is sensitive to the type of toughness test performed. Scissor tear tests maintain a sharp crack tip and give a low toughness value. In contrast, the trouser tear test allows the crack tip to blunt and thereby gives rise to a larger measured toughness. This is consistent with the fact that the toughness of rat skin as measured by a trouser tear test [32] is an order of magnitude higher than that measured by a scissor tear test [31], see Table 1 . In presenting the data for skin penetration, the skin toughness value has been taken from a scissor tear test, as the chamfered edges of a hypodermic or suture needle maintain a sharp crack tip and thereby induce a low toughness value (see, for example, Lake and Yeoh $[45,46])$. In contrast, the results for silicone rubber penetration are given in 


\section{O Sil8800 $\left(\alpha=2.5, J_{\mathrm{IC}}=3.1 \mathrm{~kJ} \mathrm{~m}^{-2}\right) \quad \triangle$ Human skin $\left(\alpha=9.0, J_{\mathrm{IC}}=2.5 \mathrm{~kJ} \mathrm{~m}^{-2}\right)$ $\times \mathrm{B} 452\left(\alpha-3.0, J_{\mathrm{IC}}=3.8 \mathrm{~kJ} \mathrm{~m}^{-2}\right) \quad \triangle$ Sheep skin $\left(\alpha=9.0, J_{\mathrm{IC}}=2.5 \mathrm{~kJ} \mathrm{~m}^{-2}\right)$}

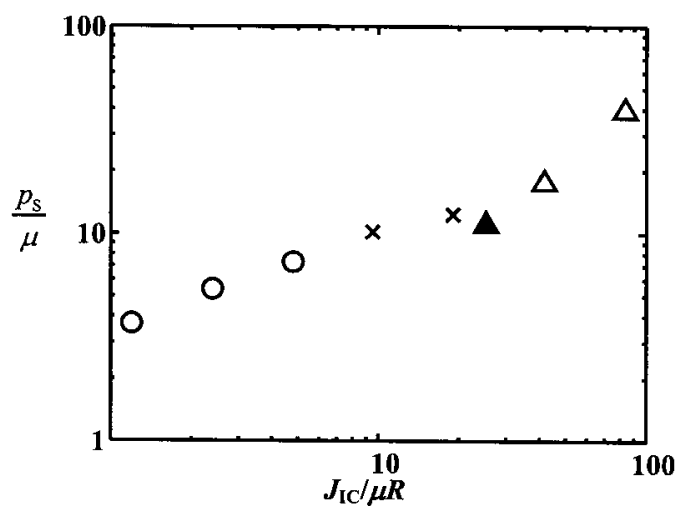

Fig. $21 p_{S} / \mu$ versus $J_{I C} / \mu R$ for the penetration of a soft solid by a sharp-tipped punch

terms of the measured toughness values from trouser tear tests, as the degree of crack blunting arising from the penetration of a soft solid by a conically-tipped punch is similar to that observed in a trouser tear test.

In broad terms, $p_{\mathrm{S}} / \mu$ increases with increasing $J_{\mathrm{IC}} / \mu R$ for all tests, see Fig. 21. Recall that the penetration theory predicts that $p_{\mathrm{S}} / \mu$ also increases with increasing strain hardening exponent $\alpha$. However, the data shown in Fig. 21 does not reflect this. This discrepancy may be due to orthotropic constitutive response and toughness of skin, or to the sensitivity of the measurements of the mechanical properties.

\section{Concluding Remarks}

Penetration experiments have been performed on silicone rubber and human skin in vivo with a sharp-tipped and flat-bottomed punch. These experiments reveal that the penetration mechanism of a soft solid depends upon the punch tip geometry: a sharp tipped punch penetrates by the formation and opening of a planar crack, while a flat-bottomed punch penetrates by the propagation of a ring crack and subsequent deformation of the solid.

The measured punch load versus displacement response demonstrates that the planar crack tunnels into the block at the speed of the advancing punch and there is a steady increase in the punch load. In contrast, the ring crack advances in a series of rapid steps and the load on the punch is unsteady. Consequently, different strategies are required to determine the steady penetration pressure on the shank cross section of the punch. A comparison of the experimental results reveals that the penetration pressure for a flat-bottomed punch is several times that of a sharp-tipped punch of equivalent diameter. It is shown experimentally that the dimensionless penetration pressure on the shank cross section of a sharp-tipped punch $p_{S} / \mu$ increases with the nondimensional group $J_{\mathrm{IC}} / \mu R$. It is appreciated that the deep penetration of skin is a more complex phenomenon than that of rubber, due to the fact that skin is a layered, orthotropic solid with a more heterogeneous structure than that of rubber.

The advantage of using rubber in penetration experiments is that it is relatively straightforward to explore a range of mechanical properties by altering the proportion of solvents, fillers and additives within the compound, and by adjusting the processing conditions. The addition of fillers, such as carbon black, increases the stiffness and tear strength of the compound [47], while the curing process controls the degree of cross-linking between polymer chains: the rubber is stiffer for greater cross-link densities. Further, the authors have found that these rubbers are useful material models for the comparison in performance of needle-free injectors [48].

\section{References}

[1] Brett, P. N., et al., 1997, "Simulation of Resistance Forces on Surgical Needles,” Proc. Inst. Mech. Eng., Part H: J. Eng. Med., 211(H), pp. 335-347.

[2] Bishop, R. F., Hill, R., and Mott, N. F., 1945, "The Theory of Indentation and Hardness Tests," Proc. Phys. Soc. London, 57, pp. 147-159.

[3] Hill, R., 1950, The Mathematical Theory of Plasticity, 1st ed., The Oxford Engineering Science Series. Oxford, pp. 125-127.

[4] Stephens, R. R., and Kramer, I. R. H., 1964, "Intra-oral Injections by High Pressure Jet," Br. Dent. J., 117(11), pp. 465-476.

[5] Katakura, H., and Tsuji, S., 1985, "A Study to Avoid the Dangers of High Speed Liquid Jets," Bull. JSME, 28(238), pp. 623-630.

[6] Stevenson, A., and Abmalek, K., 1994, "On the Puncture Mechanics of Rubber," Rubber Chem. Technol., 67(5), pp. 743-760.

[7] Shergold, O., and Fleck, N. A., 2004, "Mechanisms of Deep Penetration of Soft Solids, with Application to the Injection and Wounding of Skin," Proc. R. Soc. London, Ser. A, (in press).

[8] Ogden, R. W., 1972, "Large Deformation Isotropic Elasticity: On The Correlation of Theory and Experiment for Incompressible Rubberlike Solids," Proc. R. Soc. London, Ser. A, 326, pp. 565-584.

[9] Knight, B., 1975, "The Dynamics of Stab Wounds," Forensic Sci., 6, pp. 249-255.

[10] O'Callaghan, P. T., et al., 1999, "Dynamics of Stab Wounds: Force Required for Penetration of Various Cadaveric Human Tissues," Forensic Sci. Int., 104 pp. 173-178.

[11] Ankerson, J., et al., 1999, "Puncture Resistance and Tensile Strength of Skin Simulants," Proc. Inst. Mech. Eng., Part H: J. Eng. Med., 213, pp. 493-501.

[12] Frick, T. B., et al., 2001, "Resistance Force Acting on Suture Needles," J. Biomech., 34, pp. 1335-1340.

[13] Figge, F. H. J., and Barnet, D. J., 1948, “Anatomic Evaluation of a Jet Injection Instrument Designed to Minimize Pain and Inconvenience of Parenteral Therapy," J. Am. Acad. Nurse Pract., 3(4) pp. 197-206.

[14] Ankerson, J., et al., 1998, "The Effect of Knife Blade Profile on Penetration Force in Flesh Simulants," Technology, Law and Insurance, 3, pp. 125-128.

[15] Towler, M. A., et al., 1988, "Influence of Cutting Edge Configuration on Surgical Needle Penetration Forces,” J. Emerg. Med., 6, pp. 475-481.

[16] Black, D., Marks, R., and Caunt, A., 1985, "Measurement of Scalpel Blade Sharpness and its Relationship to Wound Healing," Bioengineering and the skin, 1, pp. 111-123.

[17] Livingston, D. I., et al., 1961, "Visco-Elastic Factors in the Strength of Elastomers Under Complex Stress by a Puncture Method," J. Appl. Polym. Sci., 5, pp. $442-451$.

[18] Charrier, J. M., et al., 1986, "Penetration of Elastomeric Blocks by Needles," J. Elast., 18(4), pp. 200-210.

[19] Jansen, L. H., and Rottier, P. B., 1958, "Some Mechanical Properties of Human Abdominal Skin Measured on Excised Strips: A Study of their Dependence on Age and How They are Influenced by the Presence of Striae," Dermatologica, 117, pp. 65-183.

[20] Shergold, O., 2004, The Mechanics of Needle-Free Injection, in Department of Mechanical Engineering, Cambridge University Press, Cambridge, p. 200.

[21] Clark, J. A., Cheng, J. C. Y., and Leung, K. S., 1996, "Mechanical Properties of Normal Skin and Hypertrophic Scars," Burns, 22, pp. 443-446.

[22] Manschot, J. F. M., and Brakkee, A. J. M., 1987, "Characterization of in vivo Mechanical Skin Properties Independent of Measuring Configuration," Bioengineering and the skin, 3, pp. 1-10.

[23] Vogel, H. G., 1987, "Age Dependence of Mechanical and Biochemical Properties of Human Skin. Part I. Stress-Strain Experiments, Skin Thickness, and Biochemical Analysis," Bioeng Skin, 3, pp. 67-91.

[24] Flynn, D. M., et al., 1998, "A Finite Element Based Method to Determine the Properties of Planar Soft Tissue,” J. Biomech. Eng., 120, pp. 202-210.

[25] Lanir, Y., and Fung, Y. C., 1974, "Two-Dimensional Mechanical Properties of Rabbit Skin-II. Experimental Results,” J. Biomech., 7, pp. 171-182.

[26] Reihsner, R., Balogh, B., and Menzel, E. J., 1995, “Two-Dimensional Elastic Properties of Human Skin in Terms of an Incremental Model at the in Vivo Configuration," Med. Eng. Phys., 17, pp. 304-313.

[27] Rivlin, R. S., and Thomas, A. G., 1953, "Rupture of Rubber. I. Characteristic Energy for Tearing," J. Polym. Sci., 10, pp. 291-318.

[28] Purslow, P. P., 1989, "Fracture of Non-Linear Biological-Materials: Some Observations from Practice Relevant to Recent Theory," J. Phys. D, 22, pp. $854-856$.

[29] Vogel, H. G., 1987, "Age Dependence of Mechanical and Biochemical Properties of Human Skin. Part II. Hysteresis, Relaxation, Creep and Repeated Strain Experiements," Bioeng Skin, 3, pp. 141-176.

[30] Atkins, A. G., and Mai, Y.-W., 1985, "Elastic and Plastic Fracture: Metals, Polymers, Ceramics, Composites, Biological Materials," Ellis Horwood, Chichester.

[31] Pereira, B. P., Lucas, P. W., and Swee-Hin, T., 1997, "Ranking the Fracture Toughness of Thin Mammalian Soft Tissues Using the Scissors Cutting Test," J. Biomech., 30, pp. 91-94.

[32] Purslow, P., 1983, "Measurement of the Fracture Toughness of Extensible Connective Tissues," J. Mater. Sci., 18, pp. 3591-3598.

[33] Wang, Y. L., and Attenburrow, G. E., 1994, "Strength of Brazilian Goatskin Leathers in Relation to Skin and Animal Characteristics," J. Soc. Leather Technol. Chem., 78(2), pp. 55-60.

[34] Granot, I., et al., 1991, "Skin Tearing in Broilers in Relation to Skin Collagen: Effect of Sex, Strain and Diet," Poult Sci., 70, pp. 1928-1935.

[35] Purslow, P. P., 1983, "Positional Variations in Fracture Toughness, Stiffness 
and Strength of Descending Thoracic Pig Aorta," J. Biomech., 18, pp. 947953.

[36] Looney, M., et al., 2002, RIRDC Publication No. 02/105 Enhancing the Unique Properties of Kangaroo Leather, 2002, Rural Industries Research and Development Corporation.

[37] McCrum, N. G., Buckley, C. P., and Bucknall, C. B., 1997, Principles of Polymer Engineering, Oxford University Press, Oxford.

[38] Benbow, J. J., and Roesler, F. C., 1957, Proc. Phys. Soc. London, Sect. B, 70, p. 210.

[39] Thomas, A. G., 1958, "Rupture of Rubber. V. Cut Growth in Natural Rubber Vulcanizates," J. Polym. Sci., 31, pp. 467-480.

[40] Greensmith, H. W., and Thomas, A. G., 1955, "Rupture of Rubber. III. Determination of Tear Properties," J. Polym. Sci., 18, pp. 189-200.

[41] Bhowmick, A. K., Gent, A. N., and Pulford, C. T. R., 1983, "Tear Strength of Elastomers under Threshold Conditions," Rubber Chem. Technol., 56, pp. 226-232.

[42] Gent, A. N., and Tobias, R. H., 1982, “Threshold Tear Strength of Elas- tomers,” J. Polym. Sci., Polym. Phys. Ed., 20, pp. 2051-2058.

[43] Roff, W. J., and Scott, J. R., 1971, Fibres, Films, Plastics and Rubbers, Butterworths, London.

[44] Shergold, O., and Fleck, N. A., 2004, "The Uniaxial Consitutive Behaviour of Pig Skin and Silicone Rubber Across a Wide Range of Strain Rates," Int. J. Impact Eng., (submitted).

[45] Lake, G. J., and Yeoh, O. H., 1978, "Measurement of Rubber Cutting Resistance in the Absence of Friction," Int. J. Fract., 14, pp. 509-526.

[46] Lake, G. J., and Yeoh, O. H., 1987, "Effect of Crack Tip Sharpness on the Strength of Vulcanized Rubbers,” J. Polym. Sci., Part B: Polym. Phys., 25, pp. 1157-1190.

[47] Harris, J., and Stevenson, A., 1987, "On the Role of Nonlinearity in the Dynamic Behaviour of Rubber Components," Int. J. Veh. Des., 8, pp. 553-577.

[48] Shergold, O. A., Fleck, N. A., and King, T. K., 2004, "The Penetration of a Soft Solid by a Liquid Jet, with Application to the Administration of a NeedleFree Injection," J. Biomech. (submitted). 